\title{
Vitreous Substitutes
}

\author{
William Joseph Foster, MD, PhD \\ Research Professor, Department of Physics, The University of Houston, Houston, TX, and Clinical \\ Associate Professor, Department of Ophthalmology, Weill Medical College of Cornell University at, \\ The Methodist Hospital, Houston, TX, 617 Science \& Research Building 1, Houston, TX 77204-5005
}

\section{Abstract}

Modern vitreoretinal surgery is a young science. While tremendous developments have occurred in instrument design and technique since Machemer first described vitrectomy surgery in 1973[1], the application of advanced materials concepts to the development of intra-ocular compounds is a particularly exciting area of research. To date, the development of vitreous substitutes has played a significant role in enabling the dramatic and progressive improvement in surgical outcome, but perhaps no other area of research has the potential to further improve the treatment of retinal detachment and other retinal disorders. While prior research has focused solely upon the ability of a compound to re-attach the retina, future research should seek to enable the surgeon to inhibit the development of proliferative vitreoretinopathy and re-detachment, the integration of stem-cell therapies with surgical retina, long-term delivery of medications to the posterior segment, and the promotion of more rapid and complete visual rehabilitation.

\section{Keywords}

vitreous substitute; polymer; retinal detachment; vitrectomy; retina; tissue engineering

\section{Introduction}

Retinal detachment is a significant cause of morbidity, with an incidence between 10.1 and 17.9 per 100,000 persons in the United States[2,3,4]. Currently, one of the most common techniques to repair many retinal detachments combines pars-plana vitrectomy, laser- or cryotherapy, and placement of a vitreous substitute into the vitreous cavity. Despite improvements in equipment and technique, the rate of re-detachment in complex retinal detachments can average about 23.5\% [5]. It is common for the properties of the vitreous and the vitreoretinal interface to play a critical role in the creation of a retinal detachment[6] and so, increased attention to this interface will likely provide significant benefits. In addition, although the available vitreous substitutes have gradually improved, with recent advances in soft condensed matter physics, nano- and bionanotechnology, and developmental biology, the field of vitreous substitutes is poised to produce novel compounds that result in improved surgical outcomes and more rapid and complete visual rehabilitation.

The introduction of materials into the posterior segment of the eye as a surgical adjunct dates back to the early part of the $20^{\text {th }}$ century, with the introduction of air into the vitreous cavity by Ohm[7]. Over time, a variety of compounds have been adapted for use in the eye, and many of these have found an important place in the armamentarium of the modern vitreoretinal 
surgeon. A wonderful review of the history of the clinical application of vitreous substitutes can be found in the textbook Vitreous Substitutes by Peyman and Schulman[8].

The aim of this paper is to review the properties of the vitreous, review current vitreous substitutes, discuss the physical properties that determine how vitreous substitutes function, discuss problems and limitations of current vitreous substitutes, and finally review current efforts to develop improved vitreous substitutes that address the problems. In order to better understand the role of vitreous substitutes, it is important to first understand the basic properties of the vitreous.

\section{The Vitreous Body}

The vitreous body is the clear substance present in the posterior portion of the eye, behind the lens. It is approximately $99 \%$ water by weight and is a paucicellular natural hydrogel that is made up primarily of unbranched Type II collagen fibrils and hyaluronic acid [9]. Within the vitreous body, the non-crosslinked collagen forms a semi-random polymer network that runs from one end of the vitreous cavity to the other. Hyaluronic acid is interspersed within the collagen polymer network and is also present in regions of liquefied vitreous. Hyaluronic acid is a glycosaminoglycan, made up of two alternating monosaccharides $(N$-acetylglucosamine and glucuronic acid, linked by glycoside bonds), and forms a 1,000-10,000 MW unbranched, coiled polyanion that has a high hydrated specific volume $(2,000-3,000 \mathrm{cc} / \mathrm{g})$. The concentration of hyaluronic acid varies from $0.03-0.10 \%$ in human vitreous [9].

The vitreous is non-uniform in density. Cloquet's canal, the central portion of the vitreous that is present anterior to the optic nerve, frequently contains thin, multilayered, fenestrated sheaths of basal lamina tissue [9]. In addition, there is a 100-200 $\mu \mathrm{m}$-thick layer of solid cortical gel adjacent to the retina, ciliary body, and lens [9]. The vitreous is firmly attached to the anterior retina at the vitreous base, where collagen fibers penetrate the retina and attach to the basement membrane of the ciliary epithelium and peripheral retinal pigment epithelium (RPE)[10]. The retina is otherwise in contact with the vitreous along its inner surface, at the internal limiting membrane.

In young children, the vitreous is firm and acts as a viscoelastic damper. This action is thought to be due to the presence of hyaluronic acid [9] and the uniform distribution of osmotic pressure aids in the attachment of the retina to the underlying tissues. The osmotic pressure of the immature vitreous may play a role in maintaining retinal attachment in the case of retinal trauma. As a person ages, the vitreous develops liquefied pockets, characterized by a paucity of collagen [9], and eventually separates from the retina completely, except for the most anterior retina. This change has been credited to aggregation of the collagen fibrils into thicker cables [11] or enzymatic collagen breakdown [12] as well as changes and thickening of the basement membrane of the retina that result in loss of collagen fibril adherence [9] except within the vitreous base, in the anterior eye, where collagen fibrils remain firmly attached to the basement membrane of the RPE.

\section{The Role of the Vitreous in Rhegmatogenous Retinal Detachments}

As a person ages, the vitreous body normally undergoes a non-uniform transition from a gellike substance in a young child to a more fluid-like substance in an older adult. Associated with this transition are a number of vision threatening phenomena such as macular holes, retinal tears, retinal detachments, and vitreous hemorrhage. The mechanism for these phenomena is thought to involve traction of the liquefying vitreous gel on the retina and retinal vessels when convective currents are created in the vitreous by eye movements[13]. 
During the acute phase of this separation (known as a posterior vitreous detachment or PVD), the vitreous may be abnormally attached to the retina at some focal point. The vitreous will naturally move within the eye during normal eye movement and in the process can create a tear or hole in the retina at the point of adhesion. This retinal tear should be repaired promptly, using laser or cryopexy, as it can lead to retinal detachment with the risk of blindness.

Treatment of a retinal detachment involves relieving the traction and blocking egress of fluid through the hole by re-approximation of the retina to the underlying tissues. Details of treatment options for this condition (which include vitrectomy surgery, scleral buckling surgery, and pneumatic retinopexy, as well as combinations of these surgeries) have been thoroughly reviewed by Wilkinson and Rice [13]. An increasingly common technique to achieve successful re-attachment of the retina is vitrectomy surgery.

\section{Vitrectomy Surgery}

When a patient undergoes a vitrectomy, much of the vitreous is removed by using aspiration and cutting techniques to relieve the traction on the retina. The eye is then typically filled with air or a perfluronated hydrocarbon, and the retina is re-attached to the back of the eye by surface tension[14]. Thermal laser photocoagulation is then applied around any retinal tears or holes to create an inflammatory scar. Finally, a vitreous substitute is injected into the eye to maintain the retina in position. Vitreous substitutes in common use include sulfur hexafluoride gas $\left(\mathrm{SF}_{6}\right)$, n-perfluorpropane gas $\left(\mathrm{C}_{3} \mathrm{~F}_{8}\right)$, air, and polydimetylsiloxane.

\section{Gases}

Frequently a gas (air, sulfur hexafluoride, or n-perfluoropropane) is introduced into the eye to hold the retina against the back of the eye (the RPE) until a scar is formed around the retinal tear, between the retina and the underlying tissue[15]. This process can take weeks, and during this time, the installed compound must remain in contact with the retinal hole. For this reason, patients who have received intraocular gas are usually positioned for a week or more in a facedown position, that many find difficult to maintain. Obviously, holes located in the inferior retina are not easily amenable to closure by intraocular gas[16].

\section{Silicone Oil}

Silicone oil (polydimethylsiloxane) has been used since 1962[17] for complex retinal tears, for inferior tears, or in patients unable to position themselves. Given its lower surface tension at the water interface ( $\sim 30 \mathrm{mN} / \mathrm{m}$ as opposed to $\sim 70 \mathrm{mN} / \mathrm{m}$ at the gas/water interface), when compared with n-perfluoropropane, the success rate for macular hole closure is lower[18] (65\% vs. $91 \%$ ). In addition, the silicone oil should later be removed, due to its ocular side effects, such as glaucoma and corneal decompensation [19]. Unfortunately, it is difficult to remove silicon oil completely. In the US, silicon oil for use intra-ocularly is available in two viscosities, 1000 and 5000 centistokes. Both are available because surgeons differ in their preference, and their (unfounded) belief in the relative success rate of retinal detachment surgery with the two different viscosity oils despite evidence[20] that there is no difference in long term outcome.

\section{Mixtures of silicon oil and perfluorinated alkanes}

Mixtures of silicon oil and perfluorinated alkanes, with a specific gravity greater than one, have also been studied by a number of investigators $[21,22,23,24,25]$ but are not in common use. Heavier-than-water vitreous substitutes also have the disadvantage that they leave a free space in the upper part of the vitreous cavity, which might lead to the concentration of various proproliferative compounds, resulting in re-proliferation and re-detachment of the upper retina. 


\section{$\mathrm{N}$-perfluro hydrocarbons}

Because animal studies[26,27,28] appear to demonstrate inferior retinal toxicity with exposure of retinal tissues to perfluoronated hydrocarbons for more than one week, these compounds are usually only used intra-operatively. Despite this, a number of authors have argued that these compounds can be left in the eye for weeks, to improve surgical success rates in the repair of inferior retinal detachments[29,30]. Should one of these compounds prove to be non-toxic, there would be significant advantages to their use, including the fact that their specific gravity is greater than one (and thus they sink in aqueous and allow treatment of inferior retinal pathology), as well as their high oxygen carrying capacity.

\section{The Physics of intra-ocular gas and perfluorinated small-molecule liquids}

A rigorous evaluation of the behavior of intra-ocular gas has recently been conducted[14] and the primary findings are summarized here. Although it might seem natural to consider buoyancy forces when gas bubbles are immersed in liquids, this concept is applicable only in systems where the bubble is much smaller than the area of detached retina. For larger injected gas volumes, as is typically used in retinal re-attachment procedures, the re-adhesion force actually arises from the gas-liquid surface tension of a thin fluid film wetting the detached flap.

Consider the typical case of a large gas bubble that envelops the entire tear. "Since the pressure inside the gas phase is uniform, the gas exerts equal pressures on both sides of the retinal flap. Because the gas bubble has risen to the posterior of the inverted eye, there is no longer a buoyant force on the flap, which simply hangs inside a pocket of gas. However, a re-adhesion force arises from the surface tension of the wedge-shaped liquid film covering retina-RPE juncture at the base of the detached flap."[14]

In addition, an analysis of pneumatic or perfluron displacement of subretinal fluid or blood was performed[14], making use of the physical equivalence to a droplet of water dripping from a ceiling that has been previously described by the Rayleigh-Taylor instability[31]. Again, we found that interfacial tension at the gas or perfluron-aqueous interface was responsible for the displacement of sub-retinal fluid[14]. Gravity may also play a role in sub-retinal fluid displacement[32].

The situation might be better visualized if you consider an eye containing a large amount of injected gas as simply a vessel with gas in the upper portion and liquid in the lower portion of the vessel. A retinal flap tear at the top of the vessel hangs into the gas phase and clearly experiences no buoyancy force. On the other hand, re-approximating the retina to the top of the vessel allows the gas within the vessel to assume a more spherical shape, and thus, reduce the energy of the system (energy=surface tension time surface area).

In summary, although the gas bubble clearly must be in contact with the hole or tear in order to seal it, surface tension is responsible for keeping the retina re-approximated to the back of the eye. The gas only provides a gas-liquid interface and the related surface tension that seals the hole or tear in the retina. If we take into account the facts that, because of the hydrogen bonding of water molecules, the surface tension at the air-gas interface is one of the highest in nature $(72 \mathrm{mN} / \mathrm{m})$ and that gases absorb into the circulation, leaving minimal residue, it will be difficult to find a better compound to repair simple, superior retinal detachments. This is particularly true in patients who can appropriately position themselves. In order to improve on intra-ocular gases, compounds must reduce the incidence of post-operative cataract formation, re-detachment of the retina from PVR, transient ocular hypertension, or the need for extensive face-down positioning. 


\section{Complications of Vitreous Substitutes}

Emulsification and Sub-retinal material-Under non-equilibrium conditions, and with the presence of natural surfactants including fibrin, serum[33], lymphocytes, and plasma[34] within the eye, small bubbles of a vitreous substitute compound may form and obtain access to the sub-retinal space. In addition, should residual traction remain on the retinal tear, surface tension will not adequately re-approximate the retina to the RPE and again the vitreous substitute may enter the sub-retinal space.

Forming a scaffold for scar tissue-The most common cause of re-detachment of the retina after repair of a retinal detachment is proliferative vitreoretinopathy (PVR). This multicellular[35,36] scar tissue can form on the retina, within the retina, or under the retina and typically becomes clinically significant $4-8$ weeks after surgery, when it contracts and causes tractional and often rhegmatogenous detachment of the retina. Numerous studies have been conducted[37] to evaluate the effect of heparin, steroids[38], 5-fluorouracil (5-FU)[39], and other compounds to inhibit PVR. One human study, in which systemic steroids were initiated five days after surgery, showed minimal effect on PVR formation[38]. A slow-release, biodegradable system to release 5-FU demonstrated a statistically significant decrease in PVR formation in an animal model[40] but has not been tested in humans. Numerous other antiproliferative compounds have been recently reviewed[37]. Studies of combination therapies in humans have been encouraging. A study in which 62 eyes with severe (class C3 or D in the Retina Society Classification[41) PVR were infused with either balanced salt solution (BSS) or BSS with heparin and dexamethasone[42] was notable for a non-statistically-significant trend toward reduction in recurrent PVR and re-attachment in a single operation, although the trial was halted prematurely because of an increased risk of post-operative hemorrhage. A second study [43], in which low-molecular-weight heparin and 5-FU were added to the infusion, found a $50 \%$ reduction $(12.6 \%$ vs. $26.4 \%)$ reduction in PVR and a statistically significant difference in the number of patients requiring re-operation. Unfortunately, the final visual acuity between the treated and placebo groups did not meet statistical significance.

A related disorder, with reported re-detachment rates between 15\%[44] and 49\%[45] is perisilicon oil proliferation. This proliferation typically occurs in places in which the vitreous substitute is not in contact with the retina.

Both of these disorders illustrate the critically important problem of gliotic scar tissue formation and the importance of approaches that have the ability to inhibit the formation of these membranes.

Tissue Toxicity-Silicon oil has been reported to be toxic to the retina[46,47,48,49] and to extract lipophilic substances (such as retinol and cholesterol) from the retina[50], although some studies have failed to corroborate these finding [51,52]. Perfluoronated oils [53,54,55] and mixtures of silicon oil and perfluoronated oils $[21,22,25]$ have all been found to have significant retinal and ocular toxicity.

Cataract-All currently utilized vitreous substitutes, including gases[56,57] and silicon oils $[58,59,60,61]$ have long been known to cause progression of cataract.

Glaucoma-Compounds that can emulsify can interfere with the function of the trabecular meshwork and lead to glaucoma. This is the second most common cause of vision loss known to occur with silicon oil $[62,63,64,65,66]$. In addition, transiently elevated intraocular pressure is known to commonly occur with gasses if they expand postoperatively. 
Keratopathy-Chronic exposure of the corneal endothelium to silicon oil and related compounds is known $[67,68]$ to damage the endothelial cells and can lead to corneal decomposition, pain from bullous keratopathy, and blindness.

It is interesting that, despite prolonged contact between silicon oil and the corneal endothelium, the cornea may remain clear because aqueous entry into the corneal stroma is impeded by the silicon oil that is adherent to the corneal endothelium[69,70,71]. It is only when the silicon oil is removed from the anterior chamber that the cornea becomes edematous and opaque[72].

\section{Alternative Compounds}

Over the years, many attempts to develop vitreous substitutes have been conducted using a trial-and-error approach[73]. Materials that have been experimentally investigated include a number of modified natural hydrogels, partially fluorinated silicon oils, and organic molecules. Included in this list are: perfluorophenanthrene[74], perfluorotri- $n$-propylamine[75], polymethyl-3,3,3-trifluoropropylsiloxane-co-dimethylsiloxane[76], poly(2-hydroxyethyl acrylate)[77], semifluorinated alkanes[78], silicone gel[79], methylated collagen[80], collagen/hyaluronic acid mixtures[81], hydroxypropylmethyl cellulose[82], crosslinked poly (vinyl) alcohol[83], polymethylacrylamidoglycolate methyl ester[84], and crosslinked poly(1vinyl-2-pyrrolidinone)[85].

All of these compounds either depend on surface tension[14] or are structurally similar to silicone oils and presumably depend on surface tension and the (as yet incompletely determined) other mechanisms through which silicone oils may act.

\section{Magnetic fluids}

A clever approach to maintaining retinal attachment without total dependence upon surface tension is the synthesis of a magnetic analog of silicon oil[86], and its use as a vitreous substitute together with a magnetic band around the eye[87]. The magnetic field that results from the band (or scleral buckle) would, presumably, aid in maintaining the vitreous substitute in contact with the retinal tear that underlies the magnetic portion of the buckle. Of course, vitreous traction on the retina must first be relieved and the surface tension at the vitreous substituteaqueous interface must be significant to promote re-attachment of the retina and to avoid subretinal vitreous substitute. Toxicity studies on this compound are crucial, given the known toxicity of the constituents. It also should be taken into consideration if the magnetic band, now encased in scar tissue, will have to be removed after successful repair of the retina. Removal of the band will carry with it the possibility of re-detachment of the retina, but may be required in order to remove most of the magnetic vitreous substitute. In addition, the difficulty in obtaining MRI imaging studies in such patients must be considered.

\section{Polymeric vitreous substitutes}

Recent efforts have been made to develop formed vitreous substitutes. In addition to replicating the formed vitreous jelly present in a child's eye, these compounds allow the retina to be reattached using physical mechanisms other than surface tension. Typically, osmotic swelling [88] is utilized to maintain the retina in position. This is particularly important in the treatment of inferior retinal detachments and complex retinal detachments including giant retinal tears, conditions that have historically resulted in poor surgical outcomes.

These compounds may possess significant advantages in that they typically require face-up (rather than face-down) positioning for a limited period of time (1-2 days) whereas 7 or more days of face down positioning are currently required of most patients after surgery. In addition, given that the compounds are typically more than $90 \%$ water, their index of refraction is similar to water, avoiding a large refractive change and allowing faster visual rehabilitation. Finally, 
by decreasing convective currents within the eye, they may decrease the extremely high incidence of post-operative cataract and need for an additional surgery.

Perhaps the most critical problem to be addressed in such materials is the possibility that the material will act as a scaffold for PVR or diabetic membranes, leading to additional traction on the retina and recurrent retinal detachment.

Based upon recent developments in tissue engineering $[89,90]$ and developmental biology, modulation of the Young's modulus of the vitreous substitute[91,92,93] seems to provide a mechanism to inhibit cellular proliferation and thus might result in better anatomic surgical outcomes.

\section{Conclusions}

In summary, the currently available vitreous substitutes are able to maintain retinal attachment in many cases but there is significant room for improvement. Toxicity and other problems have been reviewed. By applying novel tissue engineering and biomaterials technology to the development of vitreous substitutes, it will be possible to significantly improve surgical success, patients' comfort, and visual rehabilitation.

\section{Expert Commentary}

While current vitreous substitutes possess some extremely useful features, there are significant limitations. Fortunately, due to the recent developments in tissue engineering, bionanotechnology, and developmental biology, the field of vitreous substitute development is poised to produce markedly improved therapeutics.

Key to this development will be the integration of advanced tissue engineering concepts, including mechanical and chemical control of cell differentiation and growth, as well as longterm drug delivery systems into vitreous substitutes.

\section{Five-year view}

Over the next five to ten years, we can expect a movement toward developing biomimetic compounds that not only maintain retinal apposition, but utilize novel materials and biotechnology concepts to control metaplasia of cells in contact with various materials, inhibit PVR formation, and promote the survival of retinal cells. This will result in improved biocompatibility, given the current focus on the biophysics and bioengineering of the materialtissue interface.

Utilization of a variety of different physical concepts, including osmotic swelling, to reapproximate the retina will allow faster visual rehabilitation, improved patient comfort and compliance, and better surgical outcomes.

Finally, by combining physical re-attachment of the retina with long-term drug delivery, retinal therapeutics can be delivered over sustained intervals to maintain retinal health.

\section{Key Issues}

- Vitreous substitutes in current use work, but have significant limitations.

- Biomaterials are being developed based upon a careful consideration of the biophysics $\&$ bioengineering of the material-tissue interface.

- Biomimetic compounds can allow control of cell metaplasia and PVR formation. 
- These newer vitreous substitutes may utilize different physical properties, such as osmotic swelling[88], rather than surface tension[14], to maintain retinal apposition.

- Prolonged drug delivery of anti-scarring, anti-neoplastic, and other compounds will be integrated into some vitreous substitutes.

\section{Acknowledgements}

The author has benefited from the generous support of the National Eye Institute of the National Institutes of Health (EY017112) as well as from a National Academies/Keck Futures Grant.

\section{References}

Reference annotations $*$ of interest or $* *$ of considerable interest

1. Machemer R, Buettner H, Norton EW, Parel JM. Vitrectomy: a pars plana approach. Trans Am Acad Ophthalmol Otolaryngol 1971;75(4):813-820. [PubMed: 5566980]

2. Rowe JA, Erie JC, Baratz KH, et al. Retinal detachment in Olmsted County, Minnesota, 1976 through 1995. Ophthalmology 1999;106:154-159. [PubMed: 9917797]

3. Wilkes SR, Beard CM, Kurland LT, Robertson DM, O'Fallon WM. The incidence of retinal detachment in Rochester, Minnesota, 1970-1978. Am J Ophthalmol 1982;94:670-673. [PubMed: 7148948]

4. Haimann MH, Burton TC, Brown CK. Epidemiology of retinal detachment. Arch Ophthalmol 1982;100:289-292. [PubMed: 7065947]

5. Ünlü N, Kocaogbrevelan H, Acar MA, Sargin M, Aslan BS, Duman S. Outcome of Complex Retinal Detachment Surgery after Silicone Oil Removal. Int Ophthalmol 2004;25:33-36. [PubMed: 15085974]

6. Charles, S. Vitreous microsurgery. Williams \& Wilkins; Baltimore, USA: 1981.

7. Olm J. Über die Behandlung der Netzhautablösung durch operative Entleerung der Subretinalen Flüssigkeit und Einspritzung von Luft in den Glaskörper. Albrecht von Graefes Arch Ophthalmol 1911;79:442-465.

8**. Peyman GA, Schulman JA. Appleton \& Lange, East Norwalk Connecticut, USA. Vitreous Substitutes. 1995A comprehensive review of the early history of vitreous substitute development

9. Balazs EA. Fine Structure and Function of Ocular Tissues. The Vitreous. Int Ophthalmol Clin 1973;13:169-187. [PubMed: 4204768]

10. Hogan MJ. The Vitreous, Its Structure, and Relation to the Ciliary Body and Retina. Proctor Award Lecture. Invest Ophthalmol 1963;51:418-445. [PubMed: 14073657]

11*. Sebag J, Balazs EA. Morphology and Ultrastructure of Human Vitreous Fibers. Invest Ophthalmol Vis Sci 1989;30:1867-1871. [PubMed: 2759801]A careful presentation of the structure and variations with age of the vitreous

12. Los LI, van der Worp RJ, van Luyn MJ, Hooymans JM. Age-Related Liquefaction of the Human Vitreous Body: LM and TEM Evaluation of the Role of Proteoglycans and Collagen. Invest Ophthalmol Vis Sci 2003;44:2828-2833. [PubMed: 12824219]

13. Wilkinson, CP.; Rice, TA. Michels Retinal Detachment. 2. Mosby; St. Louis: 1997.

14*. Foster WJ, Chou T. Physical mechanisms of gas and perfluron retinopexy and sub-retinal fluid displacement. Phys Med Biol 2004;49:2989-2997. [PubMed: 15285260]A quantitative evaluation of the forces involved in re-attachment of the retina with various vitreous substitutes

15. Lincoff H, Kreissig I, Jakobiec F, Iwamoto T. Remodeling of the cryosurgical adhesion. Arch Ophthalmol 1981;99:1845-1849. [PubMed: 7295139]

16. Chang TS, Pelzek CD, Nguyen RL, Purohit SS, Scott GR, Hay D. Inverted pneumatic retinopexy: a method of treating retinal detachments associated with inferior retinal breaks. Ophthalmology 2003;110:589-594. [PubMed: 12623827]

17. Cibis PA, Becker B, Okun E, Canaan S. The Use of Liquid Silicone in Retinal Detachment Surgery. Arch Ophthalmol 1962;68:590-599. [PubMed: 14021325] 
18. Lai JC, Stinnett SS, McCuen BW. Comparison of silicone oil versus gas tamponade in the treatment of idiopathic full-thickness macular hole. Ophthalmology 2003;110:1170-1174. [PubMed: 12799243]

19. Federman JA, Schubert HD. Complications Associated with the Use of Silicone Oil in 150 Eyes after Retina-Vitreous Surgery. Ophthalmology 1988;95:870-876. [PubMed: 3174036]

20. Scott IU, Flynn HW Jr, Murray TG, Smiddy WE, Davis JL, Feuer WJ. Outcomes of complex retinal detachment repair using 1000- vs 5000-centistoke silicone oil. Arch Ophthalmol 2005;123:473-478. [PubMed: 15824219]

21. Majid MA, Hussin HM, Biswas S, Haynes RJ, Mayer EJ, Dick AD. Emulsification of Densiron-68 used in inferior retinal detachment surgery. Eye. 2007e-pub ahead of print

22. Sandner D, Engelmann K. First experiences with high-density silicone oil (Densiron) as an intraocular tamponade in complex retinal detachment. Graefes Arch Clin Exp Ophthalmol 2006;244:609-619. [PubMed: 16205937]

23. Tognetto D, Minutola D, Sanguinetti G, Ravalico G. Anatomical and functional outcomes after heavy silicone oil tamponade in vitreoretinal surgery for complicated retinal detachment: a pilot study. Ophthalmology 2005;112:1574. [PubMed: 16139666]

24. Rizzo S, Genovesi-Ebert F, Vento A, Cresti F, Di Bartolo E, Belting C. A new heavy silicone oil (HWS 46-3000) used as a prolonged internal tamponade agent in complicated vitreoretinal surgery: a pilot study. Retina 2007;27:613-620. [PubMed: 17558325]

25. Theelen T, Tilanus MA, Klevering BJ. Intraocular inflammation following endotamponade with highdensity silicone oil. Graefes Arch Clin Exp Ophthalmol 2004;242:617-620. [PubMed: 15029505]

26. Chang S, Sparrow JR, Iwamoto T, Gershbein A, Ross R, Ortiz R. Experimental Studies of Tolerance to Intravitreal Perfluoro-n-octane Liquid. Retina 1991;11:367-474. [PubMed: 1813951]

27. Sparrow JR, Matthews GP, Iwamoto T, Ross R, Gershbein A, Chang S. Retinal tolerance to intravitreal perfluoroethylcyclohexane liquid in the rabbit. Retina 1993;13:56-62. [PubMed: 8460281]

28. Velikay M, Wedrich A, Stolba U, Datlinger P, Li Y, Binder S. Experimental Long-term Vitreous Replacement With Purified and Nonpurified Perfluorodecalin. Am J Ophthalmol 1993;116:565-570. [PubMed: 8238215]

29. Rofail M, Lee LR. Perfluoro-n-octane as a postoperative vitreoretinal tamponade in the management of giant retinal tears. Retina 2005;25:897-901. [PubMed: 16205570]

30. Sirimaharaj M, Balachandran C, Chan WC, et al. Vitrectomy with short term postoperative tamponade using perfluorocarbon liquid for giant retinal tears. Br J Ophthalmol 2005;89:1176-1179. [PubMed: 16113376]

31. Chandrasekar, S. Hydrodynamic and Hydromagnetic Stability. Dover; New York: 1981.

32. Stopa M, Lincoff A, Lincoff H. Analysis of forces acting upon submacular hemorrhage in pneumatic displacement. Retina 2007;27:370-374. [PubMed: 17460594]

33. Heidenkummer HP, Kampik A, Thierfelder S. Experimental evaluation of in vitro stability of purified polydimethylsiloxanes (silicon oil) in viscosity ranges from 1000 to 5000 centistokes. Graefes Arch Clin Exp Ophthalmol 1991;87:226-228.

34. Bartov E, Pennarola F, Savion N, et al. A quantitative in vitro model for silicon oil emulsification: Role of blood constituents. Retina 1992;12(3 suppl):S23-S27. [PubMed: 1455078]

35. Guidry C. The role of Müller cells in fibrocontractive retinal disorders. Prog Retinal Eye Res 2005;24:75-86.

36. Pastor JC, de la Rua ER, Martin F. Proliferative vitreoretinopathy: risk factors and pathobiology. Prog Retinal Eye Res 2002;21:127-144.

37*. Sun JK, Arroyo JG. Adjunctive Therapies for Proliferative Vitreoretinopathy. Int Ophthalmol Clin 2004;44:1-10. [PubMed: 15211172]A good recent review of small-molecule therapeutics for PVR inhibition

38. Koerner F, Mertz A, Gloor B, et al. Postoperative retinal fibrosis- a controlled clinical study of systemic steroid therapy. Graefes Arch Clin Exp Ophthalmol 1982;90:810-816.

39. Asaria RH, Kon CH, Bunce C, et al. Adjuvant 5-fluorouracil and heparin prevents proliferative vitreoretinopathy: results from a randomized, double-blind, controlled clinical trial. Ophthalmology 2001;108:1179-1183. [PubMed: 11425671] 
40*. Borhani H, Peyman GA, Rahimy MH, et al. Suppression of experimental proliferative vitreoretinopathy by sustained intraocular delivery of 5-FU. Int Ophthalmol 1995;19:43-49. [PubMed: 8537196]Perhaps the first small-molecule drug system to have significant efficacy in PVR inhibition. The sustained delivery of drug appears critical to its success. When coupled with more advanced materials and integrated with a vitreous substitute system, the concepts illustrated here may aid in obtaining improved surgical outcomes

41. The Retina Society Terminology Committee. The classification of retinal detachment with proliferative vitreoretinopathy. Ophthalmology 1983;90:121-125. [PubMed: 6856248]

42. Williams RG, Chang S, Comaratta MR, et al. Does the presence of heparin and dexamethasone in the vitrectomy infusate reduce reproliferation in proliferative vitreoretinopathy? Graefes Arch Clin Exp Ophthalmol 1996;234:496-503. [PubMed: 8858355]

43. Asaria RHY, Kon CH, Bunce C, et al. Khaw Pt, Aylward GW. Adjuvant 5-fluorouracil and heparin prevents proliferative vitreoretinopathy: results from a randomized, double-blind, controlled clinical trial. Ophthalmology 2001;108:1179-1183. [PubMed: 11425671]

44. Federman JL, Schubert HD. Complications associated with the use of silicon oil in 150 eyes after retina-vitreous surgery. Ophthalmology 1988;95:870-876. [PubMed: 3174036]

45. Lewis H, Burke JM, Abrams GW, et al. Perisilicon proliferation after vitrectomy for proliferative vitreoretinopathy. Ophthalmology 1988;94:583-591. [PubMed: 3174019]

46. Ni C, Wang WJ, Albert DM, et al. Intravitreous silicon injection: Histopathologic findings in a human eye after 12 years. Arch Ophthalmol 1986;101:1399-1401. [PubMed: 6615306]

47. Honda Y, Ueno S, Miura M, et al. Silicon oil particles trapped in the subretinal space: Complications after substitution of the vitreous. Ophthalmologica 1986;192:1-5. [PubMed: 3703476]

48. Kirchhof B, Tavakolian U, Paulmann H, et al. Histopathological findings in eyes after silicon oil injection. Graefes Arch Clin Exp Ophthalmol 1986;224:34-37. [PubMed: 3943733]

49. Shikishima H, Ohki K, Machi N, et al. Effects and distribution of intravitreally or subretinally injected silicon oil identified in rabbit retina using osmium tetroxide method. Jpn J Ophthalmol 1992;36:369478.

50. Refojo MF, Leong FL, Chung H, et al. Extraction of retinol and cholesterol by intraocular silicon oils. Ophthalmology 1988;95:614-618. [PubMed: 3174023]

51. Suzuki M, Okada T, Takeuchi S, et al. Effect of silicon oil on ocular tissues. Jpn J Ophthalmol 1990;35:282-291. [PubMed: 1770668]

52. Pastor JC, Lopez MI, Saornil MA, et al. Intravitreal silicon and fluorosilicone oils: Pathologic finding in rabbit eyes. Acta Ophthalmol 1992;70:651-658. [PubMed: 1471491]

53. Miyamoto K, Refojo MF, Tolentino FL, et al. Fluorinated oils as experimental vitreous substitutes. Arch Ophthalmol 1986;104:1053-1056. [PubMed: 3729774]

54. Chang S, Zimmerman NJ, Iwamoto T, et al. Experimental vitreous replacement with perfluorotributylamine. Am J Ophthalmol 1987;103:29-37. [PubMed: 3799787]

55. Velikay M, Wedrich A, Stolba U, et al. Experimental long-term vitreous replacement with purified and nonpurified perfluorodecalin. Am J Ophthalmol 1993;116:565-570. [PubMed: 8238215]

56. Fineberg E, Machemer R, Sullivan P, et al. Sulfur hexafluoride in owl monkey vitreous cavity. Am J Ophthalmol 1875;79:67-76. [PubMed: 803269]

57. Lincoff H, Mardirossian J, Lincoff A, et al. Intravitreal longevity of three perfluorocarbon gases. Arch Ophthalmol 1980;98:1610-1611. [PubMed: 7425922]

58. Federman JL, Schubert HD. Complications associated with the use of silicon oil in 150 eyes after retina-vitreous surgery. Ophthalmology 1988;95:870-876. [PubMed: 3174036]

59. Leaver, PK. Silicon-oil injection in the treatment of massive preretinal retraction. In: McPherson, A., editor. New and Controversial Aspects of Vitreoretinal Surgery. Mosby; St. Louis MO: 1977. p. 397-401.

60. Cockerham W, Schepens CL, Freeman HM. Silicon injection in retinal detachment. Mod Probl Ophthalmol 1969;8:625-540.

61. Moisseiev J, Bartov E, Cahane M, et al. Cataract extraction in eyes filled with silicon oil. Arch Ophthalmol 1992;110:1649-1651. [PubMed: 1444927] 
62. Grey RHB, Leaver PK. Results of silicone oil injection in massive preretinal retraction. Trans Ophthalmol Soc UK 1977;97:238-241. [PubMed: 273330]

63. Ni C, Wang WJ, Alber DM, et al. Intravitreous silicone injection: Histopathologic findings in a human eye after 12 years. Arch Ophthalmol 1983;101:1399-1401. [PubMed: 6615306]

64. Leaver PK, Grey RH, Garner A. Complications following silicone-oil injection. Mod Probl Ophthalmol 1981;20:290-294. [PubMed: 548759]

65. Alexandridis E, Daniel H. Results of silicon oil injection into the vitreous. Dev Ophthalmol 1981;2:24-27. [PubMed: 7262406]

66. Al-Jazzaf AM, Netland PA, Charles S. Incidence and Management of Elevated Intraocular Pressure After Silicone Oil Injection. Journal of Glaucoma 2005;14:40-46. [PubMed: 15650603]

67. McCuen BW II, Dejuan E Jr, Landers MB III, et al. Silicone oil in vitreoretinal surgery: II. Results and complications. Retina 1985;5:198-205. [PubMed: 3835614]

68. Gao R, Neubauer L, Tang S, et al. Silicone oil in the anterior chamber. Graefes Arch Clin Exp Ophthalmol 1989;227:106-109. [PubMed: 2721976]

69. Casswell AG, Gregor ZJ. Silicon oil removal: I. The effect of silicon oil on the cornea. Br J Ophthalmol 1992;110:1649-1651.

70. Beekhuis WH, van Rij G, Zivojnovic R. Silicon oil keratopathy: Indications for keratoplasty. Br J Ophthalmol 1985;69:247-253. [PubMed: 3888251]

71. Setala K, Ruusuvaara P, Punnonen E, et al. Changes in corneal endothelium after treatment of retinal detachment with intraocular silicon oil. Acta Ophthalmol 1989;67:37-42. [PubMed: 2773638]

72. McCuen BW II, De Juan E Jr, Lander MB III, et al. Silicon oil in vitreoretinal surgery: II. Results and complications. Retina 1985;5:198-205. [PubMed: 3835614]

73*. Colthurst MJ, Williams RL, Hiscott PS, Grierson I. Biomaterials Used in the Posterior Segment of the Eye. Biomaterials 2000;21:649-665. [PubMed: 10711963]A comprehensive overview of materials utilized in the posterior segment prior to 2000

74. Peyman GA, Conway MD, Soike KF, Clark LC. Long-Term Vitreous Replacement in Primates with Intravitreal Vitreon or Vitreon Plus Silicone. Ophthalmic Surg 1991;22:657-664. [PubMed: 1792032]

75. Bryan JS, Friedman SM, Mames RN, Margo CE. Experimental Vitreous Replacement with Perfluorotri-n-propylamine. Arch Ophthalmol 1994;112:1098-1102. [PubMed: 8053824]

76. Doi M, Refojo MF. Histopathology of Rabbit Eyes with Silicone-Fluorosilicone Copolymer Oil as Six Months Internal Retinal Tamponade. Exp Eye Res 1995;61:469-478. [PubMed: 8549688]

77. Chan IM, Tolentino FI, Refojo MG, Fournier G, Albert DM. Vitreous Substitute. Experimental Studies and Review. Retina 1984;4:51-59. [PubMed: 6729266]

78. Zeana D, Becker J, Kuckelkorn R, Kirchhof B. Perfluorohexyloctane as a long-term vitreous tamponade in the experimental animal. Experimental perfluorohexyloctane substitution. Int Ophthalmol 1999;23:17-24. [PubMed: 11008894]

79. Peyman GA, Conway MD, Karacorlu M, et al. Evaluation of Silicone Gel as a Long-term Vitreous Substitute in Non-human Primates. Ophthalmic Surg 1992;23:811-817. [PubMed: 1494435]

80. Liang CP, Peyman GA, Serracarbassa P, Calixto N, Chow AA, Rao P. An Evaluation of Methylated Collagen as a Substitute for Vitreous and Aqueous Humor. Int Ophthalmol 1998;22:13-18. [PubMed: 10090443]

81. Nakagawa M, Tanaka M, Miyata T. Evaluation of Collagen Gel and Hyaluronic Acid as Vitreous Substitutes. Ophthalmic Res 1997;29:409-420. [PubMed: 9380343]

82. Fernandez-Vigo J, Refojo MF, Verstraeten T. Evaluation of a Viscoelastic Solution of Hydroxypropyl Methylcellulose as a Potential Vitreous Substitute. Retina 1990;10:148-152. [PubMed: 2402557]

83. Yamauchi, A. Synthetic Vitreous Body of PVA Hydrogel. In: DeRossi, D.; Kajiwara, K.; Osada, Y.; Yamauchi, A., editors. Polymer Gels. Plenum Press; New York: 1991. p. 127-134.

84. Chirila TV, Sharp C, Moore SR, et al. Synthetic Hydrogel as an Artificial Vitreous Body. A OneYear Animal Study of Its Effects on the Retina. Cells Mater 1995;5:83-96.

85. Hong Y, Chirila TV, Vijayasekaran S, et al. Crosslinked Poly(1-vinyl-2-pyrrolidinone) as a Vitreous Substitute. J Biomed Mat Res 1996;30:441-448. 
86. Phillips JP, Li C, Dailey JP, Riffle JS. Synthesis of Silicone Magnetic Fluids for Use in Eye Surgery. J Mag Mag Mater 1999;194:140-148.

87. Vadala, TP.; Goff, JD.; Zhang, Q.; Dailey, JP.; Riffle, JS. Polysiloxane Magnetic Fluids for Use in Eye Surgery. Proc. of the 29th Annual Meeting of the Adhesion Society; 2006.

88. Foster WJ, Aliyar HA, Hamilton P, Ravi N. Internal Osmotic Pressure as a Mechanism of Retinal Attachment in a Vitreous Substitute. J Bioact Compat Pol 2006;21:221-235.

89**. Flanagan LA, Ju YE, Marg B, Osterfield M, Janmey PA. Neurite branching on deformable substrates. Neuroreport 2002;13:2411-2415. [PubMed: 12499839]A key paper from the neuroscience literature that illustrates how modulation of the mechanical properties of substrates can produce marked effects on cell growth and differentation, including inhibition of gliosis

90*. Engler AJ, Sen S, Sweeney HL, Discher DE. Matrix elasticity directs stem cell lineage specification. Cell 2006;126:677-89. [PubMed: 16923388]A dramatic illustration of the power of modulation of the mechanical properties of the extracellular matrix in determining cell fate, in this case in adult mesenchymal stem cells

91. Foster, WJ.; Janmey, PA.; Flannagan, LA.; Ravi, N. Proliferative Vitreoretinopathy Inhibition Utilizing a Nanostructured Vitreous Substitute. The Meeting of the American Society of Retina Specialists; Palm Springs, CA, USA. 30 November-5 December 2007;

92. Foster, WJ.; Janmey, PA.; Flanagan, LA.; Sawyer, ES. A novel, formed vitreous substitute to repair battlefield ocular trauma and complex retinal detachments: A mechanical mechanism of PVR ("scar tissue”) inhibition. The Advanced Technology Applications for Combat Casualty Care (ATACCC) Meeting; Saint Pete Beach, Florida, USA. 13-15 August 2007;

93. Foster WJ, Janmey PA, Flanagan LA. A Mechanical Mechanism of Proliferative Vitreoretinopathy Inhibition in Vitreous Substitutes. Investig Ophthalmol Vis Sci 2006;47:E-Abstract 3823. 